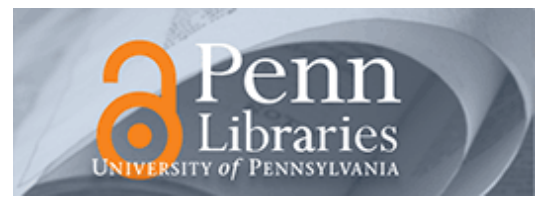

University of Pennsylvania

ScholarlyCommons

6-1-2008

\title{
Justifying a Presumption of Restraint in Animal Biotechnology Research
}

Autumn Fiester

University of Pennsylvania, fiester@mail.med.upenn.edu

Follow this and additional works at: https://repository.upenn.edu/bioethics_papers

Part of the Life Sciences Commons

\section{Recommended Citation}

Fiester, A. (2008). Justifying a Presumption of Restraint in Animal Biotechnology Research. Retrieved from https://repository.upenn.edu/bioethics_papers/68

Suggested Citation:

Fiester, Autumn. (2008). "Justifying a Presumption of Restraint in Animal Biotechnology Research." The American Journal of Bioethics. Vol.8:6. pp. $36-44$

This is an electronic version of an article published in The American Journal of Bioethics. The American Journal of Bioethics is available online at: http://www.informaworld.com/smpp/title content=t713606739

This paper is posted at ScholarlyCommons. https://repository.upenn.edu/bioethics_papers/68

For more information, please contact repository@pobox.upenn.edu. 


\title{
Justifying a Presumption of Restraint in Animal Biotechnology Research
}

\author{
Abstract \\ Articulating the public's widespread unease about animal biotechnology has not been easy, and the first \\ attempts have not been able to provide an effective tool for navigating the moral permissibility of this \\ research. Because these moral intuitions have been difficult to cash out, they have been belittled as \\ representing nothing more than fear or confusion. But there are sound philosophical reasons supporting \\ the public's opposition to animal biotechnology and these arguments justify a default position of \\ resistance I call the Presumption of Restraint. The Presumption of Restraint constitutes a justificatory \\ process that sets out the criteria for permitting or rejecting individual biotechnology projects. This \\ Presumption of Restraint can be overridden by compelling arguments that speak to a project's moral and \\ scientific merit. This strategy creates a middle-of-the-road stance that can embrace particular projects, \\ while rejecting others. The Presumption of Restraint can also serve as a model for assessing moral \\ permissibility in other areas of technological innovation. \\ Disciplines \\ Life Sciences

\section{Comments} \\ Suggested Citation: \\ Fiester, Autumn. (2008). "Justifying a Presumption of Restraint in Animal Biotechnology Research." The \\ American Journal of Bioethics. Vol.8:6. pp. $36-44$ \\ This is an electronic version of an article published in The American Journal of Bioethics. The American \\ Journal of Bioethics is available online at: http://www.informaworld.com/smpp/ \\ title content=t713606739
}


Justifying a Presumption of Restraint in Animal Biotechnology Research

\author{
Autumn Fiester, PhD \\ Senior Fellow \\ University of Pennsylvania Center for Bioethics
}

Suite 320, 3401 Market Street

Philadelphia, PA 19104

Phone: 215-573-2602

Fax: 215-573-4931

fiester@mail.med.upenn.edu 


\title{
Justifying a Presumption of Restraint in Animal Biotechnology Research
}

\begin{abstract}
Articulating the public's widespread unease about animal biotechnology has not been easy, and the first attempts have not been able to provide an effective tool for navigating the moral permissibility of this research. Because these moral intuitions have been difficult to cash out, they have been belittled as representing nothing more than fear or confusion. But there are sound philosophical reasons supporting the public's opposition to animal biotechnology and these arguments justify a default position of resistance I call the Presumption of Restraint. The Presumption of Restraint constitutes a justificatory process that sets out the criteria for permitting or rejecting individual biotechnology projects. This Presumption of Restraint can be overridden by compelling arguments that speak to a project's moral and scientific merit. This strategy creates a middle-of-the-road stance that can embrace particular projects, while rejecting others. The Presumption of Restraint can also serve as a model for assessing moral permissibility in other areas of technological innovation.
\end{abstract}


Justifying a Presumption of Restraint in Animal Biotech Research

In the decade following the cloning of Dolly the Sheep in 1996, the science of animal biotechnology has made steady -- even remarkable -- progress, but the public's comfort with these new technologies has not increased. Although over half of the public is opposed to this research ( $\mathrm{Saad} 2004$; PIFB 2005), there is very little active dialogue between the proponents of this science and the critics. One explanation for the absence of a robust debate is the challenge of articulating the public's opposition in a form that doesn't simply reduce to a pure emotivist reaction, which is quickly dismissed by the proponents as parochial or naive. Attempts to give a substantive critique have faced difficult objections from the advocates of this science. On the other side of this fledgling dialogue is not so much an articulated pro-animal biotech position but an attack on the anti-biotech arguments that lays bare the difficulty of capturing theoretically the ethical problems with many of the projects of this new science. But in the absence of compelling arguments critiquing biotechnology, or at least certain parts of it, the net result is a presumption in favor of it. Most worrisome about the state of this debate is what is being implicitly condoned. Having no effective argument to rein in animal biotechnology or distinguish the moral permissibility of various projects, we are tacitly permitting all of them. 
Of course, all research in the US that involves animals is regulated at one level: research protocols need to pass the scrutiny of the Institutional Animal Care and Use Committee (IACUC) that protects animals from unnecessary pain and suffering and mandates adequate pain relief during research procedures. There is also the selfregulation imposed by the scientists themselves, and in their peer-review protocol assessments. But in the US to date, there is no over-arching ethical framework or gatekeeping mechanism that determines which projects are ethically justified and which are not.

As a way of offering more concrete ethical guidance to animal biotechnology research, I will argue for a position that I call the "Presumption of Restraint:" a default position of wariness that must be overcome by morally compelling reasons in order to justify a particular project's moral legitimacy or permissibility. This is not an argument for the prohibition of animal biotech research and commercialization that follows from some anti-biotech arguments. The Presumption of Restraint amounts to a "proceed with caution" stance that can be overcome rather than a blanket opposition, and it stands in direct contrast to the overly permissive approach that currently prevails.

To understand the need for a stronger articulation of the critique of animal biotechnology, I begin with a review of the often-cited anti-biotech arguments that have recurred in the literature, and I highlight the key objections raised against these arguments. While these arguments are quite suggestive, they are not powerful enough as they stand to justify the Presumption of Restraint. Using specific cases of animal 
biotechnology as a focal point for the discussion, as well as insights gleaned from these anti-biotech arguments, I present the argument for restraint, which I believe goes a long distance in articulating the public's intuition that this science is moving too fast and without due reflection and scrutiny. This approach lays out legitimate reasons for concern about these new technologies, while showing the way in which some - or even many - of them might be morally justified. Rather than condemn or embrace all animal biotechnology projects, this approach constitutes a middle-of-the-road position that escapes the "all or nothing" character of the debate as it now stands.

\section{The Current Critiques of Animal Biotechnology}

The recent anti-biotechnology arguments have been made against the backdrop of strong public opposition to this new science. Public opinion data consistently shows that more than half of Americans oppose animal biotechnology, with the numbers differing slightly depending on the type of modification. A 2004 Gallup poll, for example, found that $64 \%$ of Americans believe that animal cloning is morally wrong (Saad 2004), and a 2005 poll conducted for the Pew Initiative on Food and Biotechnology found a similar $66 \%$ opposed to animal cloning (PIFB 2005). Interestingly, opposition to animal cloning remains high even among individuals who rarely attend religious services, normally an indicator of more liberal views. From their latest poll, the Pew Initiative found that 56\% of those polled who attend religious services a few times a year or less oppose animal cloning (PIFB 2005). If asked about the genetic modification of animals -- rather than 
about animal cloning -- the percentage opposed drops slightly, but remains remarkably consistent over a three-year tracking period. Pew researchers found $58 \%$ opposed to the genetic modification of animals in $2003,57 \%$ in 2004 , and $56 \%$ in $2005-$ indistinguishable given the margin of error (PIFB 2003; PIFB 2004; PIFB 2005).

In the US debate, three main anti-biotechnology arguments are frequently made: (1) the science amounts to "playing God;" (2) the science violates the natural world by either crossing sacrosanct species boundaries or compromising animal's integrity; and, (3) it has harmful consequences to animals, the environment, or human beings. While all of these arguments are suggestive, the current formulations leave them open to obvious objections that are hard to overcome, making them easy targets of the proponents of animal biotech. After reviewing the pitfalls in these arguments as they stand, I will utilize their insights to support a "softer" conclusion: not a ban, but a stance of restraint.

The most common anti-biotechnology stance is the claim that this science amounts to "man playing God" (Kass and Wilson 1998, p. 18), a role to which we are said not to be entitled. On this argument, animal biotechnology is an attempt by human beings to be divine. It crosses an important moral line between what Jeremy Rifkin has described as facilitating the creation of life (as in assisted reproduction) and engineering life (Rifkin 1998). In the former, human beings are the builders using a God-given blueprint, whereas in the second, they are the architects. The force of this argument is usually carried by the feelings of revulsion that people experience when they contemplate cloning and other genetic modifications. On this emotive argument, these feelings are 
viewed as constituting all the justification one needs to reject biotechnology because there is a profound "wisdom of repugnance" (Kass and Wilson 1998) underlying this reaction. ${ }^{1}$

While this critique likely resonates on first glance with many people, it is a hard claim to defend. Its first weakness is that it is too coarse an instrument to distinguish between long-accepted breeding practices and the modifications the public finds threatening and problematic. It not only brands all current biotechnology projects as morally impermissible, but extends back in time to all past instances of genetic engineering, low-tech and high tech, many of which have wide public support (Burkhardt 1998). Modification of animals, and in the process the creation of new species, is not new. And moving forward, if this argument is correct, no projects in this new science are ethically justifiable - no matter how great the gain for human welfare and no matter how small the manipulation. On this argument, there can be no innocuous or neutral genetic engineering because all of it makes the same fundamental mistake: assuming the role of God. Therefore there can be no moral continuum of animal biotechnology from permissible to impermissible. Context, motivation, means, purpose, scope and consequence are irrelevant in deciding the moral worthiness of the project because the whole science violates an important moral principle. But this does not square with the data we have about the public's moral intuitions. Support for genetic modification of animals increases significantly when the purpose of the modification serves an important human need. For example, the Pew research found that $57 \%$ of those polled found that 
producing organs for human transplant was a good reason to genetically alter animals (Pew 2003). When the modification involves plants rather than animals, the purpose of the modification correlates even more dramatically with public support. In this same study, researchers found that $81 \%$ considered the production of better pharmaceuticals to be a good reason to genetically modify plants, $71 \%$ considered the reduction of pesticides to be a good reason, and $69 \%$ thought the creation of heart-healthy fats was a good reason (Pew 2003). Because the "playing God" argument cannot clearly demarcate a moral line that distinguishes projects that violate moral intuitions from those that don't, it amounts to an overly broad critique that cannot hone in on the essential criterion for moral impermissibility in this area science.

Of course, if these arguments were valid, then the radical conclusion that all biotechnology -- animal or plant -- is impermissible and should cease would simply be true, whether it squared with our current intuitions or not. But these arguments are not strong enough to secure this radical conclusion. As a rejoinder to the "playing God" argument, not only do opponents argue that we have been modifying organisms throughout human history and that only the means of modification have changed, but they argue that it is equally plausible to claim that we are sanctioned by God to conduct this science, evidenced by the intellectual acuity humankind was granted by their Creator that motivates scientific curiosity. They argue that if the criticism of the new animal biotechnology is the means of modification of life, then the real argument is about the negative consequences to the animals, not a prohibition against playing God. If the 
criticism is that such work is not permitted by God, then it is just as plausible to argue that this science has God's blessing, just as all past scientific progress did. Ethicist Gary Comstock, for example, coming from the perspective of an evangelical Protestant, argues that God wants human beings to pursue science and he believes God endorses scientific endeavors like biotechnology (Comstock 2001). It isn't playing God; it's doing what God has given researchers the mental gifts to do. Animal cloning researcher Randall Prather makes a similar argument in an essay on animal biotechnology:

But does biotechnology sound as if it could be unbiblical, evil, or an enterprise with which we Christians should not associate?...Is this a form of "creating new life," tampering with something sacred, somehow playing God?...Should reproductive biotechnologies be used on domestic animals? Since God does not command against it, and it can increase the quality of life and help prevent famine and human suffering, the answer is then: "Yes, these technologies should be perfected and applied..." (Prather 1998).

Since debates hinging on interpretations of God's will are interminable at best, Prather's argument is a powerful rejoinder. Given these weaknesses in the argument, the "playing God" argument has no real force.

A second critique of animal biotechnology is that it constitutes a violation of nature because it tampers with life in a way that undermines the natural order of things. Again, this argument can be seen as a "close cousin" of the "playing God" concern, but it takes a very different tact. Although this critique speaks to many forms of animal biotechnology, it specifically targets transgenesis -- the introduction of a foreign gene into the genome of an organism of a different species -- as a science that violates species boundaries that are important not to cross. This argument from "unnaturalness" seems to 
have more clarity than the "playing God" argument because it focuses on only a subset of technologies and does not rely on a particular understanding of divine will. However, it relies instead -- not less problematically -- on difficult philosophical or scientific concepts like "animal integrity" or "species." Take the "animal integrity" argument first.

Although they offer a working definition of "integrity," advocates of using this concept as a means of moral evaluation for biotechnology are remarkably quick to conclude that the concept is not an objectively grounded one and that giving the notion real content will require a great deal of (future) work. In a highly cited essay arguing the merits of the concept, authors Bovenkerk et al begin with a working definition of integrity as: "wholeness and intactness of the animal and its species-specific balance, as well as the capacity to sustain itself in an environment suitable to the species" (Bovenkerk, Brom and Van Den Berg 2002, p. 17). But in their own discussion they admit that the definition is actually very hard to defend, concluding: "The concept of integrity thus does not refer to an objective state of affairs, but to one that we feel is important to preserve.... While it does not refer to empirically ascertainable biological facts, we can still establish intersubjective criteria for its application. Through moral discussion, we can reach agreement about which sorts of actions do and do not lead to violations of integrity" (Bovenkerk, Brom and Van Den Berg 2002, p. 5-6). But if "animal integrity" really means "manipulations of animal life that we condone," rather than "an animal's rightful biological state or condition," then the notion of "integrity" is doing no work. "Animal integrity" is really determined at the end of the moral conversation; it is not a tool to 
guide moral reflection about animal biotechnology. While this concept might gain content after public dialogue about what constitutes morally permissible and impermissible modifications of animals, it is not now a concept that can be legitimately used to critique or assess current animal biotech projects.

The alternative argument from "unnaturalness" employs the concept "species" rather than "animal integrity," and it encounters parallel problems, as Jason Scott Robert and Francoise Baylis have recently pointed (Robert and Baylis 2003). On this argument, animal biotechnology projects that violate species boundaries are morally problematic. Building a moral argument on what appears to be an objective, scientific category seems to be a good argumentative strategy, but philosophers and biologists are quick to point out the fluidity of what we take to be a species, undermining the notion that these are natural or fixed kinds. This argument has been effectively made by Robert and Baylis who argue, “[E]ssentialism - or at least stock conceptions of essentialism according to which a species is identified by essential intrinsic properties - is at odd with evolutionary biology...As against what was once commonly presumed, there would appear to be no such thing as fixed species identities" (Robert and Baylis 2003, pp. 5-6). There may be a legitimate concern here related to the mixing of species at the speed and level at which we now seem (or will soon be) capable, but the argument as it stands is not powerful or qualified enough to overcome this science-based objection.

An additional problem that plagues both of the "unnaturalness" arguments is that the force of the claims is often carried by the emotive response that people have to animal 
biotechnology. Arguments that turn on people's emotional reactions are often derisively labeled as "Yuck Factor", arguments. The problem with arguments that are purely emotive is that they lack the ability to persuade anyone who doesn't already share these same intuitions or feelings because they are not backed by rational argument or justification. Scientists, for example, who are pursuing various projects in animal biotechnology, presumably do not feel revulsion in response to the work they are doing. They might legitimately ask in response to arguments that appeal to emotion: "Why should I feel that way?" -- a question that must be answered if the argument is to have any true weight. "Yuck factor" arguments, then, must always be anchored by rational justification, even if they have an initial appeal to emotional reaction. In the case at hand, the real justification for opposition to certain types of biotechnology cannot remain a moral intuition or feeling, but must be grounded in the moral judgment that underlies that feeling. And that moral judgment has not been well articulated by this camp.

As an illustration of an emotive strategy in the "unnaturalness" arguments, I return to the "animal integrity" argument. Bovenkerk et al write, "When we envision the future in which we buy eggs from a warehouse housing hundreds of rows of flesh colored humps created from what we once knew as chickens, a feeling of discomfort comes over us. We -- or many of us, anyway -- have a moral intuition that changing chickens into living egg machines is wrong. The moral notion that gives voice to this intuition is “integrity."” (Bovenkerk, Brom and Van Den Berg 2002, p. 5-6, italics added). In other words, "integrity" is supposed to be the normative explanation or moral judgment that 
underlies the feelings of revulsion. So far, so good. If "animal integrity" can now be cashed out independent of our moral feelings, it could plausibly function as the justification or anchor that the argument needs. But what does "integrity" turn out to be? Again Bovenkerk et al: "And even if we could not reach this agreement ["about which sorts of actions do and do not lead to violations of integrity"], the notion of integrity still has an important function, namely to clarify the moral debate and criticize existing practices. Integrity can give opponents of [this] thought experiment a way to voice their criticism of the creation of living egg machines..." (Bovenkerk, Brom and Van Den Berg 2002, p. 5-6). Bovenkerk et al treat the task of defining "animal integrity" as optional, believing it can still be used as a term of critique in the biotechnology debate even without being given independent content. But if we fail to give convincing content to the notion of "integrity," then the term refers to nothing but our emotive response to those existing practices. Without a substantive account, that critique will simply amount to another way of saying "Yuck," which has little argumentative power against those whose intuitions differ from one's own. All of this is not to say that our moral intuitions or feelings can play no role in making a moral judgment; it is simply to argue that many have mistaken that role. Feelings can legitimately serve as a starting point for reflection, raising awareness about what we ought to pay moral attention to. In fact, I will argue -as others have suggested (Midgley 2000; Streiffer 2003) -- that the feelings most people have when they contemplate projects of animal cloning or transgenesis ought to serve for us, not as an argument, but as an important red flag. But until the "unnaturalness" claims 
are backed by convincing argument or explanation, they remain merely suggestive, offering little guidance in evaluating real projects in animal biotechnology.

The other approach in the anti-biotechnology debate is a set of consequentialist arguments that critique animal biotechnology on grounds of animal pain and suffering or the adverse effects it could have on the environment or human beings. While the consequentialist strategy provides some very concrete guidance in assessing the moral permissibility of these projects, it has a serious limitation: because it hinges on adverse outcomes, it's critique only applies where untoward consequences can plausibly be argued; but the set of projects in animal biotechnology that is likely to have negative consequences is much smaller than the number and types of projects people are intuitively disturbed by. If our moral intuitions do serve as a legitimate red flag, then the consequentialist critique does not provide an adequate articulation of those moral intuitions.

Take, for example, the pain and suffering of animals in biotechnology research, the focus of most consequentialist arguments (Rollin 1995; Thompson 1997; Rollin 2003; Thompson 2003). Insofar as animals experience a unique level or type of suffering through this research, the argument against genetic engineering or transgenesis is quite powerful. But two cases need to be made in order for the consequentialist critique of animal biotechnology to be persuasive. First, animal suffering in this type of research must be shown to be significantly greater than in any other area of pharmaceutical or medical research in order for animal suffering to explain the large gap in public support 
between the former and the latter. (Polls show that only $32 \%$ of Americans believe that using animals in medical research is morally wrong, whereas twice as many Americans, $64 \%$, find animal cloning morally wrong [Saad 2004]). Making the case that the quantity of animal suffering in this new science is measurably greater than in labs that do no genetic modification is a difficult task, as others have pointed out (Greene 2002). The second case that needs to be made to bolster the consequentialist critique is that, when the animals do not suffer through this type of research, there is nothing morally problematic with this type of research (barring some other untoward consequence to the environment or to human beings). But this view does not resonate with the public's intuition. Thus, the consequentialists' argument doesn't capture the moral unease people have with the projects that cause no animal pain and suffering. In the thought experiment referred to above, in which chickens have been replaced by non-sentient, senseless egg machines (Comstock 1992; Bovenkerk, Brom and Van Den Berg 2002), there cannot be any perceived suffering on the part of the chicken-like humps because they have been engineered to have no powers of sense perception; they feel nothing. Not only can consequentialists not easily critique this futuristic creation, they are under some obligation to embrace it because this would represent a marked reduction in the overall suffering of our current egg-producers. The terrible conditions of chickens in typical American poultry farms are well known (Animal Welfare Institute 1987; Scully 2002). Animal advocates like United Poultry Concerns President Karen Davis argue, "They are proliferating lives that endure nothing but misery. It's the new horror for animals in the 
$21^{\text {st }}$ century" (Cacchioli 2002). The most consistent position for the consequentialist, then, is to embrace the animal biotech solutions that will eliminate this type of suffering.

In summary, then, while the consequentialist arguments are compelling as far as they go, they have limited scope because they rely on adverse effects, which often cannot plausibly be argued. In cases like the hypothetical senseless egg machines, the consequentialist arguments fail to capture the intuition most people have that such research is disturbing. The other anti-biotechnology arguments - the "playing God" argument and its close cousin, the argument on grounds of "unnaturalness," though both suggestive, also fail to make a compelling case for an all-out prohibition of this science, which is their aim.

Part of the problem in the current debate is that the anti-biotech arguments extend a reach that exceeds their grasp: they aim for a prohibition of all animal biotechnology, where there may only be justification for caution or restraint. But the intuitions underlying these anti-biotech arguments can be articulated as valid moral reasons that speak against our current approach to this science: blanket permission with only minimal regulation. ${ }^{3}$ On my view, the moral claims that can be made against this technology do justify a default position of restraint, and I borrow from the insights of this first set of arguments to lay out this case in the next section. 


\section{Justifying a "Presumption of Restraint" in Animal Biotechnology}

To argue for a Presumption of Restraint in this science, I want to start with projects that cannot plausibly be argued to serve the greater human good or radically improve human life, human health, or even animal health. To start here is to remove the noble purposes and motivations of many projects in animal biotechnology that may ultimately override the Presumption of Restraint in those cases, but at the stage of setting the presumption, these noble purposes detract from the critique that justifies a default position of caution. So I will focus as a case study on projects like the novelty pet or animal-as-art-object to bring into clear relief what seems most troubling about animal biotech in general.

Lest one think such projects are in the far-off future, Chicago-based artist Eduardo Kac recently commissioned the creation of a transgenic rabbit that glows green under special lighting (Allmendinger 2001). "Alba," as she's known, is the first object of what Kac hopes will be "a new art form based on the use of genetic engineering to transform natural or synthetic genes to an organism, to create unique living beings" (Kac 2002). The French lab that created Alba, the renowned French National Institute for Agricultural Research, did not conduct the research for the purpose of making art - their motivation was the development of a reliable means for identifying transgenic animals as part of their work on biopharming (the production of pharmaceuticals by using transgenic animals). But Kac's motive was art alone, and when he attempted to remove Alba from the lab to attend the Avignon art festival, the lab denied his request. While in this case, 
the creation of the rabbit was motivated for two different purposes by two different actors (Kac, for art and the French lab, for science), the next "Alba" will not be. The more recent, commercialized "GloFish" makes this clear. Modified to contain the green florescent protein (GFP) of the jellyfish and the red florescent protein (RFP) of the sea anemone, the ordinarily dull-colored zebra fish has been transformed into a fish that glows (http://www.glofish.com/). As the technology progresses unimpeded, these creatures can be expected to be just the first - and least radical -- in a long line.

The creation of a default position of restraint begins with a review of the ordinary facts that form a backdrop to all animal biotechnology. Though the very existence of "facts" is disputable by some, I take the following claims to be fairly uncontroversial. First, living organisms and the ecosystem are vastly complex and nuanced. Second, we didn't put life on this planet; we are not the causal agent of life being here. In fact, we are just two-bit manipulators compared to nature or evolution or God. Whatever or whoever is responsible for life being here, we know it was not the agency of human beings. Third, not only are human beings not the creators of life on the planet, we can barely even blueprint certain aspects of some forms of life. We can't fully explain or understand the mechanisms of life, let alone repair or restore much in the natural world (think: cancer, global warming, tears in the ozone). The complexity is beyond both our comprehension and mastery. And fourth, we depend on the natural world, and our interventions in it can threaten our existence in more and less profound ways that mirror the threat to (or destruction of) other forms of life that we have caused. Add to this set of 
facts another specifically relevant to the case of the novelty pet or animal-as-art-object. First, these creatures are alive: they are sentient, they can feel pain, and they can feel something like fear (maybe even terror). Second, like all research animals, they are dependent on human beings for their subsistence and have no control over their treatment (not only how they will fare, but what they will become), and this makes them vulnerable.

Where do these uncontroversial facts get us? More specifically, what is the moral critique of projects like Alba as art project? I argue that they lead to five ethical claims. First, the facts just noted establish that the domain that is being manipulated and altered in animal biotechnology is one of great seriousness, and this fact demands that projects in this area are treated with great care and reflection. We didn't create the genome, and we can't recreate it, even in its simplest manifestation; at this point, we can't even repair it. We are directly tampering with the building blocks of life, which we barely understand. Given the complexity of the natural world, our only rudimentary understanding of it, and what's at stake if we irrevocably harm it, the power to engineer life ought to inspire in us a feeling of "awe" -- the mixture of dread, veneration, and wonder that makes one take pause. The power to alter living beings at a rate and a level never before possible is, if nothing else, a serious venture. Frivolous projects (undertaken to amuse or entertain ourselves, done simply because we can, or done because it might be profitable) reduce a profound act to the level of play, or even jest; it makes the category-error of classifying complex living beings as mere art supplies or trivial building materials. The lack of 
seriousness in the choice to use this power to create objects for entertainment is seen most clearly when placed against the backdrop of the seemingly intractable problems we currently face, for example, world hunger or devastating disease. Expending precious scientific resources and human ingenuity on pure amusement or entertainment is frivolous and wasteful. In summary, the first moral problem with creating Alba is that using the power of genetically altering life requires a serious, pressing reason, and modification to generate novelty pets and art forms is not one.

The second moral problem with Alba is that such projects are reckless and unreflective because they proceed with a negligent lack of caution about what the broader implications and consequences of such projects might be -- not only, most obviously, consequences to animal welfare or the environment (as consequentialists rightly claim), but understood more broadly to include the transformations they may effect in our view of nature and our role in it. We have history to show us that lack of foresight about the consequences of our interventions in the natural world can be devastating, but we are now seeing interventions at a level and scale that can alter who we are, what our world looks like, what inhabits it, and our view of ourselves -- and we may not like what we see. In her essay "Biotechnology and Monstrosity," Mary Midgley writes:

Anyone who doesn't think this kind of delay [for reflection] is necessary -- anyone who wants people to rush with aplomb into this mass investment of mind and resources -- does have to be calling for a drastically changed view of nature as a whole, a view which claims that our power and knowledge are such that we can rationally expect to alter everything. To feel this kind of confidence, we would need to stop thinking of the natural world as a colossally complex system with its own laws, a system that we, as a tiny part of it, must somehow try to fit into, and 
begin instead to see it simply as the consignment of inert raw material laid out for our use (Midgley 2000, p. 12).

This transformation of how we regard the natural world may already be taking place, without our notice or concern. The speed at which we have pursued projects whose ends can't plausibly be deemed worthy or good provides evidence for Midgley’s concern because biotechnology is being placed in the category of activities that needs no justification. With biotechnology for medical or pharmaceutical application, there is an implicit argument that this scientific activity is justifiable because of the good that will come from it; with biotechnology for art or entertainment, there is a different implicit argument, namely, that this kind of scientific activity doesn't have any implications that are worth worrying about (since, if there were something to worry about in this activity, its continuance would require something to justify it like "noble ends," or something that would carry the same weight). But this stance towards unbounded animal biotechnology is both imprudent and naive. Where will transgenic projects like Alba and the Glofish take us? Who we will become because of them? What will we end up with? Is the world that we are creating one that we will still want to inhabit? And, not least of all, what havoc will we wreak on the natural world through them: on the environment, delicate ecosystems, the animals themselves? In summary, the second reason to worry morally about projects like Alba is that the rate and scale with which we can now alter the world we live in demands careful reflection of the consequences, broadly construed (not limited to risk assessment, for example), and we seem incapable of pausing long enough to 
engage in those reflections. Until the deeper questions raised by such projects have been asked and answered, bulldozing ahead with this type of genetic modification is reckless.

The third moral critique of such projects harkens back to the "playing God" argument discussed earlier. The argument against "playing God" failed because it constituted a blanket prohibition against any and all modifications of nature without being able to specify or differentiate which projects were impermissible and why. But good sense can be made of the intuition that some animal biotechnology projects overstep the boundaries of human beings' proper sphere. The normative term that gives content to this intuition is "hubris," an exaggerated pride and overconfidence about both our capacity to safely engineer life and our ability to prudently navigate the path it puts us on. "Hubris" in this sense is a secular term that does not rely on theology or divine will. It is simply the claims that we have lost the proper humility about the enormous power biotechnology affords us and that we are displaying a stunning arrogance about our ability to control it. To avoid the charge of hubris, we need to demonstrate that we can reign ourselves in, see the ill of unlimited "progress" here. In summary, the third moral reason speaking against projects like Alba is that they demonstrate an exaggerated confidence in our ability to safely and wisely employ this powerful tool; there is no demonstrated concern with such projects that this technology could go too far, which it surely could.

The fourth critique of projects like Alba is that they violate a fundamental, widely accepted principle of animal research: animals are only to be used if the cost to them is 
outweighed by an important potential benefit to human or animal life. While the moral status of animal species is far from settled, it is certain that they have the capacity to suffer. Animal suffering through biotechnology research runs the gamut from compromised health status to inflicted pain to whatever distress occurs from life in a cage (Rollin 1995). Perhaps animal suffering in science can be legitimately trumped by other serious moral considerations, but of what potency is the consideration of art or entertainment up against the suffering of a sentient creature? Whatever we decide is the morally justified role for animals in research, surely that judgment will have to take into account the very real suffering of the animals involved in that or other types of genetic modification, but that decision must involve a weighing and a balancing of the benefits to humans (or animals) on the one hand and the consequences to the research animals on the other. In research explicitly designed to create novelty pets or art forms, there is nothing on the justification side of the equation. Engaging in a project like creating a novelty pet that has nothing on the first side of the equation demonstrates an inability to recognize what's at stake on the other. How much did (does or will) Alba suffer? And how many other rabbits suffered before a glowing rabbit was achieved? That's information we don't have. But we do know that in all of the talk about this "new art form" there was no discussion of the potential suffering to the "unique living beings" that would be created in the process. Whatever the cost to sentient life in projects like these, it is surely too much for the gain. In summary, projects like Alba disregard the basic tenet of animal research: the weighing and balancing of costs and benefits. 
The fifth reason that speaks against such projects is closely related to hubris, and it cashes out the powerful feelings of revulsion or disgust many feel in reaction to certain types of biotechnology. Although Alba serves as a fairly good case study for this critique, it is the "senseless egg machines" -- the foil in the animal integrity story -- that best aide us in fleshing out those intuitions. Making rabbits glow or transforming chickens into senseless heaps of flesh debases and adulterates sentient beings by our own, direct hand. To downgrade the function of a living being or redesign life according to any purpose of our choosing shows a disregard for life as we found it. As the most powerful species on the planet, we have dominion by default. But to reduce an animal's function or recreate it based on whim or caprice reflects negatively on us as guardians. Our role should be one of "protectors," not "debasers." These projects demonstrate an inflated sense of ownership and entitlement: this is not a world of our making and the entities in it are not things, but such projects imply that they are. In summary, the fifth critique is that animals' independent existence apart from us demands a strong resistance to debasement or adulteration by our hand, and these projects unflinchingly embrace such debasement or adulteration.

In response to this fifth critique, there will no doubt be two objections. The first is that there are plenty of non-GM modes of adulteration or debasement of animal life, so this is not morally worse. The obvious response to this objection is twofold: debasement through genetic modification may not be worse than non-GM debasement, but that is not a sound defense of either mode; and, the speed and extent to which we can now 
adulterate or debase an animal at the genomic level makes the stakes much higher than past modes. A second objection is that this fifth critique requires the problematic concept of "animal integrity" we discussed earlier. But it does not. "Integrity" relies on a static conception of the characteristics of a species that is betrayed by biological facts (like evolution). Think about the following definition of "animal integrity": the "wholeness and intactness of the animal and its species-specific balance, as well as the capacity to sustain itself in an environment suitable to the species" (Bovenkerk, Brom and Van Den Berg 2002, p. 17). In contrast, "debasement" or "adulteration" is a comparative term that requires only a human-initiated action and a change from a higher status or function to a lower one. If a chicken previously could do x, and can now only do y because of something we have done to it to serve our own purposes, then we have debased it. This relies only on our everyday observations of the capacities and characteristics of different types of animals; it takes no stand on the fluidity of species, species-interests, or biological wholeness. This way of understanding what's wrong with such genetic modification makes a friendly amendment to Bovenkerk et. al. as a way of solving one problem in the concept of "integrity" (Bovenkerk, Brom and Van Den Berg 2002, p. 17-18). In their essay, they reflect on two instances of docking a dog's tail: when the tail is docked for aesthetic reasons, and when the tail must be docked for medical reasons. They argue that our intuition finds the first instance problematic but the second morally justifiable. They conclude (rightly, on my view) that this undermines the concept of biological or bodily integrity because the dog's body is mutilated in the exact 
same way in both cases. But the concept of "debasement" can make sense of our different moral judgments in the two cases. Debasement has embedded in it a criterion of intention: we "debase" or "adulterate" when we are not motivated by the promotion of the good of the entity being changed. If we must dock a dog's tail to preserve its health, we are motivated by the good of the dog. If we dock a dog's tail because our tastes run to dogs without tails, then we are motivated by self-interest and not the good of the dog. In the former case, we rescue the animal, and this reflects well on us; in the latter, we debase it. and it reflects poorly.

Based on these five moral critiques of projects like Alba, we can now justify a Presumption of Restraint in animal biotechnology. A "presumption," philosophically speaking, is a default principle that guides action in the absence of compelling, overriding reasons that speak in the action's favor. A presumption is not a prohibition; it is a set of conditions that must be met in order to "trump" the default position. I argue that these five reasons not only justify a Presumption of Restraint, but they provide the set of moral considerations we need to overcome in order to justify a project in animal biotechnology. The Alba case was a foil that facilitated the articulation of those moral considerations. Taken together, they constitute valid moral reasons -- not based on pure emotion or spurious concepts -- to proceed with caution in the area of animal biotechnology research.

Like all presumptions, this one can certainly be overridden. What would that involve? To overcome the Presumption of Restraint in animal biotechnology, a project must demonstrate: 1) a pressing reason to take the dramatic step of genetically altering 
life; 2) careful consideration of the potential consequences of the project, including the "big picture" concerns of how we are radically, possibly irreversibly, altering our world; 3) a recognition that unbridled animal biotechnology could create a world we no longer recognize or want to live in, which means that our animal biotechnology projects must be carefully, reflectively chosen; 4) a clear regard for the basic tenet of animal research, i.e., that the benefit must far outweigh the cost; and 5) a strong resistance to debasement and adulteration of sentient life.

\section{The Presumption of Restraint and the Precautionary Principle}

Given the similarity in terminology and the analogous "proceed with caution" stance, one might understandably ask how the Presumption of Restraint differs from the Precautionary Principle that now figures prominently in debates about risk assessment of new technologies. ${ }^{4}$ The answer is that these are two completely different animals. The Precautionary Principle is a moral mandate to take preemptive, preventative measures against possible harms even in the absence of certainty that such harms will occur. The clearest statement of the Precautionary Principle comes from what is known as the "Wingspread Statement," named for a conference center where the most commonly used version of the principle was formulated: "Where an activity raises threats of harm to the environment or human health, precautionary measures should be taken even if some cause and effect relationships are not fully established scientifically" (Wingspread 1998). The Presumption of Restraint, in stark contrast, is a justificatory process - a gate-keeping 
mechanism - to determine which projects should move forward and which ought to be rejected based on a set of moral considerations that extends well beyond concerns merely about safety to the environment or human health.

The Precautionary Principle is a narrow version of what I list as the second moral consideration that must be addressed for a project to override the Presumption of Restraint: in the Precautionary Principle the consequences that must be considered are reduced to an assessment of environmental and human risk; in my second moral consideration, the consequences extend much more broadly to "big picture" concerns about the way in which the project alters the world we live in and what inhabits it. One similarity between the Presumption of Restraint and the Precautionary Principle is that the burden of proof for showing that the respective criteria for permissibility has been met falls on the innovator, not the public. Again, from the Wingspread document: "In this context the proponent of an activity, rather than the public, bears the burden of proof" (Wingspread 1998).

\section{Conclusion: The Presumption of Restraint Moving Forward}

Presumptions -- and the considerations for overriding them -- are not algorithms: they do not provide a definitive diagnostic to determine which projects we ought to support and which we ought to condemn. The purpose of a presumption is to set the terms of the discussion, not to provide an algorithmic decision-procedure, and this means that reflective participants in the debate might legitimately disagree in their 
determinations of moral permissibility on any particular project. But the Presumption of Restraint in animal biotechnology accomplishes an important first step in structuring the debate: it provides sound moral reasons to critique certain projects in animal biotechnology that cannot be easily dismissed by proponents of the science. The strategy of the Presumption of Restraint is also not limited to projects in animal biotechnology: it can be employed - albeit based on different moral considerations - to assess the permissibility of projects in other arenas of novel technology, such as human cloning, enhancement, or nanotechnology. What I have articulated here is a method of assessment that may have broad uses as technological innovation moves forward. 


\section{References}

Allmendinger, U. 2001. One small hop for alba, one large hop for mankind. NY Arts Mag 6 (May 31).

Animal Welfare Institute. 1987. Factory farming: The experiment that failed. Washington DC.

Bovenkerk, B., F. Brom, and B. J. van den Bergh. 2002. Brave new birds. Hastings Cent Rep 31(1).

Burkhardt, J. 1998. The inevitability of animal biotechnology: Ethics and the scientific attitude. In Animal Biotechnology and Ethics, ed. A. Holland and A. Johnson, 114131. London: Chapman \& Hall.

Cacchioli, J. 2002. Poultry industry not ready for cloning. The Daily Times, Salisbury, MD, January 18.

Caplan, A. 1994. If I were a rich man could I buy a pancreas? Bloomington: Indiana Univ. Press.

Comstock, G. 1992. What obligations have scientists to transgenic animals? Discussion paper, Center for Biotechnology Policy and Ethics at Texas A\&M University.

Comstock, G. 2001. Ethics and genetically modified foods. Testimony for the new zealand royal commission on genetic modification. Also available online at http://www.biotech.iastate.edu/publications/IFAFS/NewZealand_paper.pdf.

Greely, H. 2003. Defining chimeras... and chimeric concerns. American Journal of Bioethics 3(3):17.

Greene, M. 2002. New dog: Old trick. Journal of Applied Animal Welfare Science 5(3):239-242

Kac, E. 2002. GFP bunny. http://www.ekac.org/gfpbunny.html\#gfpbunnyanchor.

Kass, L. and J. Q. Wilson. 1998. The Ethics of Human Cloning. La Vergne, TN: AEI Press. 
Magnus, D. 2007. Agnotology and the precautionary principle in the GEO debate. In Agnotology: The Social Production of Ignorance, edited by Robert Proctor and Londa Schiebinger. Stanford University Press, in press.

Midgley, M. 2000. Biotechnology and monstrosity. Hastings Center Report 30(5):7-15.

Pew Initiative on Food and Biotechnology. 2003. Public sentiment about genetically modified food. http://pewagbiotech.org/agtopics/index.php?TopicID=8.

Pew Initiative on Food and Biotechnology. 2004. U.S. consumer opinion divided. http://pewagbiotech.org/agtopics/index.php?TopicID=8.

Pew Initiative on Food and Biotechnology. 2005. Americans' knowledge of genetically modified foods remains low. http://pewagbiotech.org/agtopics/index.php?TopicID=8.

Prather, R. 1998. Reproductive biotechnology: An animal scientist's perspective. Perspect Sci Christ Faith 40:139-140.

Rifkin, J. 1983. Algeny. New York: Viking Press.

Robert, J. S. and F. Baylis. 2003. Crossing species boundaries. Am J Bioeth 3(3):1-13.

Rollin, B. 1995. The Frankenstein syndrome: Ethical and social issues in the genetic engineering of animals. New York: Cambridge Univ. Press.

Rollin, B. 2003. Ethics and species integrity. Am J Bioeth 3(3):15-16.

Saad, L. 2004. The cultural landscape: What's morally acceptable? Gallup Organization. http://www.gallup.com/content/print.aspx?ci=12061.

Scully, M. 2002. Dominion: The power of man, the suffering of animals and the call to mercy. New York City: St. Martin's Press.

Streiffer, R. 2003. In defense of the moral relevance of species boundaries. Am J Bioeth 3(3):37-38.

Thomson, P. 1997. Food biotechnology in ethical perspective. London: Chapman and Hall. 


\section{Thomson, P. 2003. Crossing species boundaries is even more controversial than you} think. Am J Bioeth 3(3):14-15.

\section{Wingspread Statement on the Precautionary Principle. 1998. http://www.gdrc.org/u- gov/precaution-3.html}

\footnotetext{
${ }^{1}$ It should be noted that Leon Kass, who made this argument famous, was not speaking about biotechnology in general, but was making an argument specifically against human cloning. Although it was not originally motivated by animal biotechnology, it has become the most pervasive line of attack against animal cloning and transgenesis.

2 This term was coined by Arthur Caplan (Caplan 1994).

${ }^{3}$ Of course, it needs to be repeated here that all research in the United States involving animals goes through a review of the Institutional Animal Care \& Use Committees (IACUC), and this review goes a long way in protecting animals against certain types of suffering. And it also true that scientists make their own moral assessment about which projects are morally justifiable, and that certainly serves as a second, informal, type of "review." But beyond the formal IACUC review and the informal moral assessment by the scientists or funding agency, animal biotech research in the US has very wide, loose guidelines and boundaries.

${ }^{4}$ For an excellent historical account of the development and evolution of the precautionary principle, see Magnus 2007.
} 